\title{
DEDICATORIA \\ ESTE NÚMERO DE LA REVISTA LA CALERA ESTÁ DEDICADO A 26 AÑOS DE COOPERACIÓN SUECIA - UNIVERSIDAD NACIONAL AGRARIA
}

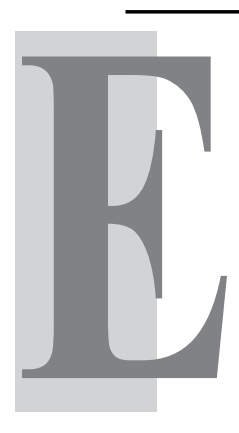

1 año 2011 marcó el fin de 26 años de cooperación sueca en la Universidad Nacional Agraria. Esta cooperación fue proveída por el pueblo y reino de Suecia, inicialmente a través de la Agencia Sueca de Cooperación Científica con los países en Desarrollo (SAREC) y, posteriormente, a través de la Agencia Internacional Sueca para el Desarrollo (Sida).

La colaboración sueca en la Universidad Nacional Agraria es considerada integral, amplia, flexible, solidaria y respetuosa. En la UNA promovió Educación, Ciencia y Tecnología, que son factores claves del desarrollo humano integral y de la sociedad. Pero sin lugar a dudas, el aporte más importante de esta colaboración en la UNA, fue la formación de talentos humanos en diferentes disciplinas, quienes en el momento actual trabajan en pro del fortalecimiento institucional y el desarrollo de Nicaragua.

El objetivo inicial de esta colaboración, fue fortalecer la investigación y la formación en Ciencias de académicos de la UNA, a través de un programa integrado de investigación y formación. La investigación se desarrollaba en Nicaragua y la educación formal en Suecia. Durante la primera parte, la cooperación se enfocó a la formación a nivel de maestría, logrando formar 22 maestros en ciencia. Tiempo después, algunos académicos de la UNA iniciaron su formación a nivel de doctorado logrando culminar esta importante tarea, para el año 2011, un total de 17 docentes.

A lo largo de los años la cooperación sueca fue creciendo en la UNA. Inicio su accionar teniendo como contraparte al departamento de producción de plantas de la Universidad Sueca de Ciencias Agrícolas, y enfocada únicamente a mejorar la producción del cultivo de frijol común. En el devenir de los años la cooperación se extendió a diferentes departamentos, tanto en SLU como en la UNA. Se involucraron así, los departamentos de producción de plantas, protección de plantas, medio ambiente, suelos, silvicultura, recursos genéticos, ciencia animal, entre otros.

Paralelo a la formación del personal, con el transcurso de los años, a través de subprogramas, la cooperación se extendió a otras áreas de la Universidad, propiciando el fortalecimiento institucional, el desarrollo del currículo, la gestión de la investigación y el posgrado, el fortalecimiento de los laboratorios, tecnologías de información y comunicación (TICs), gestión de la información para la investigación, innovación y emprendedurismo, y se proveyeron fondos para que los investigadores pudieran continuar sus líneas de investigación.

El objetivo básico del sub programa fortalecimiento institucional fue el rediseño de las capacidades de la Universidad de acuerdo a las exigencias del nuevo milenio, que le permitiera ser más flexible, competitiva y eficiente. El sub-programa desarrollo curricular apoyo la modernización de los planes de estudios, en cambio, el subprograma gestión de la investigación y el posgrado permitió definir un sistema Universitario de Ciencia Tecnología e Innovación que propiciare una cultura de generación y trasferencia de conocimientos en la institución. Además, permitió la consolidación de líneas institucionales de investigación, y el impulso de programas de maestrías, hasta llegar al momento actual, en que contamos con una propuesta de estudios de doctorado acorde a las condiciones, realidades y desafíos de nuestro país.

El sub-programa fondos competitivos de investigación permitió que gran cantidad de académicos continuaran su línea de investigación, la consolidación de grupos temáticos de investigación y que se generaran tecnologías para la familia productora nicaragüenses. Además, la cooperación sueca permitió la creación de capacidades en gestión de tecnologías de información y comunicación, lo que permitió que la institución y su accionar fueran visibles para la sociedad a lo interno y fuera de nuestras fronteras.

Logros tangenciales de esta cooperación fueron, el establecimiento de lazos de cooperación, los cuales son una realidad debido a las capacidades humanas con las cuales se cuenta en la actualidad, que permiten enfrentar desafíos como el cambio climático, el hambre, la pobreza, la marginación, entre otros; y la creación de alianzas y redes que nos permiten trabajar con instituciones del sector público y privado, productores, comunidades, a nivel regional e internacional.

La cooperación sueca en la UNA significó un antes y un después en la gestión institucional, nos permitió crecer como institución y como individuos, y nos permitió ser una institución reconocida en la formación de recursos humanos para el sector agrario, generadora de conocimientos y con una elevada proyección hacia la sociedad nicaragüense.

\section{Freddy Alemán}

Director de Investigación, Extensión y Posgrado, Universidad Nacional Agraria 